REVIEW ARTICLE

CURRENT CONCEPTS

\section{Update on Avian Influenza A (H5N1) Virus Infection in Humans}

\author{
Writing Committee of the Second World Health Organization Consultation \\ on Clinical Aspects of Human Infection with Avian Influenza A ( $\mathrm{H} 5 \mathrm{~N} 1)$ Virus*
}

\HE UNPRECEDENTED EPIZOOTIC OF AVIAN INFLUENZA A (H5N1) VIRUSES among birds continues to cause human disease with high mortality and to pose the threat of a pandemic. This review updates a 2005 report $^{1}$ and incorporates information recently published or presented at the Second World Health Organization (WHO) Consultation on Clinical Aspects of Human Infection with Avian Influenza A (H5N1) Virus. ${ }^{2}$

\section{VIRAL ECOLOGY}

Highly pathogenic avian influenza A (H5N1) viruses are entrenched among poultry in parts of Asia, Africa, and perhaps the Middle East. The highly pathogenic avian influenza $\mathrm{H} 5$ hemagglutinin has evolved into many phylogenetically distinct clades and subclades (Fig. 1) ${ }^{4,5}$ that generally correlate with antigenic differences that must be considered in the selection of candidates for H5N1 vaccines. ${ }^{6,7}$ These diverse lineages have been largely separate geographically since 2005 (Fig. 1), ${ }^{5}$ although clade 2.3 viruses from China have recently circulated in other Southeast Asian countries. ${ }^{8}$

The influenza A (H5N1) viruses that have infected humans have been entirely avian in origin, and they reflect strains circulating locally among poultry and wild birds. Avian influenza viruses can be maintained, amplified, and disseminated in live-poultry markets. Migratory birds may spread A (H5N1) viruses to new geographic regions, but their importance as an ecologic reservoir is uncertain. The spread of influenza A (H5N1) viruses appears to be principally related to the movement of poultry and poultry products, ${ }^{9,10}$ although recent outbreaks of clade 2.2 virus infection in sub-Saharan Africa, ${ }^{11}$ Egypt, and Europe may indicate introduction of the virus by wild birds. The risk of the introduction of influenza A (H5N1) viruses into North America by birds migrating through Alaska appears to be low. ${ }^{12}$

\section{EPIDEMIOLOGY OF HUMAN INFECTIONS}

\section{INCIDENCE AND DEMOGRAPHIC CHARACTERISTICS}

Despite widespread exposures to poultry infected with avian influenza A (H5N1) viruses, ${ }^{13,14}$ influenza A (H5N1) disease in humans remains very rare. Since May 2005, the numbers of both affected countries ${ }^{13}$ and confirmed cases of influenza A (H5N1) virus infection (340 cases as of December 14, 2007) have increased, in part because of the spread of clade 2.2 viruses across Eurasia and to Africa ${ }^{5,15}$ (Fig. 1 of the Supplementary Appendix, available with the full text of this article at www.nejm.org).

The median age of patients with influenza A (H5N1) virus infection is approximately 18 years, with $90 \%$ of patients 40 years of age or younger and older adults
The members of the writing committee (Abdel-Nasser Abdel-Ghafar, M.D., Tawee Chotpitayasunondh, M.D., Zhancheng Gao, M.D., Ph.D., Frederick G. Hayden, M.D., Nguyen Duc Hien, M.D., Ph.D., Menno D. de Jong, M.D., Ph.D., Azim Naghdaliyev, M.D., J.S. Malik Peiris, M.D., Nahoko Shindo, M.D., Santoso Soeroso, M.D., and Timothy M. Uyeki, M.D.) assume responsibility for the overall content and integrity of the article. Address reprint requests to Dr. Hayden at the Global Influenza Program, Department of Epidemic and Pandemic Alert and Response, World Health Organization, 20 Ave. Appia, Ch-1211, Geneva 27, Switzerland, or at haydenf@who.int.

*Affiliations of the writing committee are listed in the Appendix. The participants in the meeting of the Second World Health Organization Consultation on Clinical Aspects of Human Infection with Avian Influenza A (H5N1) Virus, Antalya, Turkey, March 19-21, 2007, are listed in the Supplementary Appendix, which is available with the full text of this article at www.nejm.org.

N Engl J Med 2008;358:261-73. 
underrepresented. ${ }^{16}$ The overall case fatality proportion is $61 \%$; it is highest among persons 10 to 19 years of age and lowest among persons 50 years of age or older. ${ }^{16}$ Whether preexisting immunity, differences in exposure, or other factors might contribute to the apparently lower frequency of infection and lethal illness among older adults is uncertain. Most patients with influenza A (H5N1) virus infection were previously healthy. Of six affected pregnant women, four have died, and the two survivors had a spontaneous abortion. ${ }^{17}$

Increases in human cases of influenza A (H5N1) have been observed during cooler months in association with increases in outbreaks among poultry (see Fig. 1 of the Supplementary Appendix). ${ }^{18}$ However, because cases have occurred yearround, clinicians must be alert to possible human infection at any time, especially in countries with outbreaks of influenza A (H5N1) among birds. To date, no cases of influenza A (H5N1) illness have been identified among short-term travelers visiting countries affected by outbreaks among poultry or wild birds, ${ }^{19}$ although clinicians in unaffected countries should consider this possibility in travelers with exposures to poultry.

Surveillance for cases of influenza A (H5N1) has focused on patients with severe illness, but milder illnesses in children, which are not pneumonic, ${ }^{20,21}$ occur. Limited seroepidemiologic studies conducted since 2003 involving villagers living with backyard poultry, workers in live-poultry markets, and health care workers suggest that asymptomatic or mild human influenza A (H5N1) virus infection is rare (Table 1 of the Supplementary Appendix). ${ }^{14}$

\section{TRANSMISSION}

Direct avian-to-human H5N1 virus transmission is the predominant means of human infection, although the exact mode and sites of influenza A (H5N1) virus acquisition in the respiratory tract are incompletely understood. Handling of sick or dead poultry during the week before the onset of illness is the most commonly recognized risk factor. ${ }^{22,23}$ Most patients have acquired A (H5N1) infection from poultry raised inside or outside their houses. Slaughtering, defeathering, or preparing sick poultry for cooking; playing with or holding diseased or dead poultry; handling fighting cocks or ducks that appear to be well; and consuming raw or undercooked poultry or poultry products have all been implicated as potential
Figure 1 (facing page). Evolution of the Hemagglutinin and Other Key Mutations Associated with Virulence or Drug Resistance in Avian Influenza A (H5N1) Virus.

The phylogenetic tree is for the hemagglutinin gene of highly pathogenic avian influenza $A(\mathrm{H} 5 \mathrm{Nl})$ viruses. The geographic distributions refer to avian isolates, and the tree is based on publicly available sequences. Clade 0 includes viruses that were first recognized to cause human infections in Hong Kong Special Administrative Region in 1997. Viruses from clades and subclades $0,1,2.1,2.2,2.3$, and 7 have caused human disease. Clade 1 viruses predominated in Vietnam, Thailand, and Cambodia in the early phase of the outbreak (2004-2005), and clade 2.1 viruses are endemic in Indonesia. Clade 2.2 viruses were associated with a major outbreak of $\mathrm{H} 5 \mathrm{Nl}$ disease in migratory birds in Qinghai Lake, China, and have since spread, causing avian disease in Central and South Asia, the Middle East, Europe, and Africa and human disease in western Asia, the Middle East, and Africa. Clade 2.3 has become dominant in southern China and has also been detected in adjacent countries. (Modified from the WHO Web site: www.who.int/csr/disease/avian_influenza/ guidelines/nomenclature/en/index.html.) The influenza genome contains eight individual segments of RNA, several of which encode two proteins. Within clade 1 or clade 2.1 viruses, polymerase basic protein 2 (PB2) Glu627Lys is observed in some isolates of human viruses but not in avian viruses. ${ }^{3}$ Some human clade 1 viruses without PB2 627Lys have PB2 701Asn; clade 2.2 viruses of both human and avian origin have PB2 Glu627Lys. ${ }^{4}$ The importance of sequence variations in $\mathrm{NSl}$, in which most influenza A ( $\mathrm{H} 5 \mathrm{N1}$ ) viruses contain a carboxyl-terminus-sequence motif that mediates binding to various cellular proteins bearing a PDZ domain, remains to be determined.

risk factors. ${ }^{21-24}$ The defeathering of dead wild swans was implicated in one case cluster. ${ }^{25}$

The influenza A (H5N1) virus can also infect multiple mammalian hosts, ${ }^{26,27}$ including domestic cats ${ }^{28}$ and dogs. ${ }^{29}$ None have been implicated in influenza A (H5N1) virus transmission to humans yet, but any animal infected with the virus theoretically poses a risk of transmission and of being a host for viral adaptation to mammals. ${ }^{26}$

Clusters of human influenza A (H5N1) illness with at least two epidemiologically linked cases have been identified in 10 countries and have accounted for approximately one quarter of cases. ${ }^{20,21,24,30-32}$ Most clusters have involved two or three persons; the largest affected eight. More than $90 \%$ of case clusters have occurred among blood-related family members, suggesting possible genetic susceptibility, although one statistical model indicated that these clusters might have occurred because of chance alone. ${ }^{33}$ Most persons 


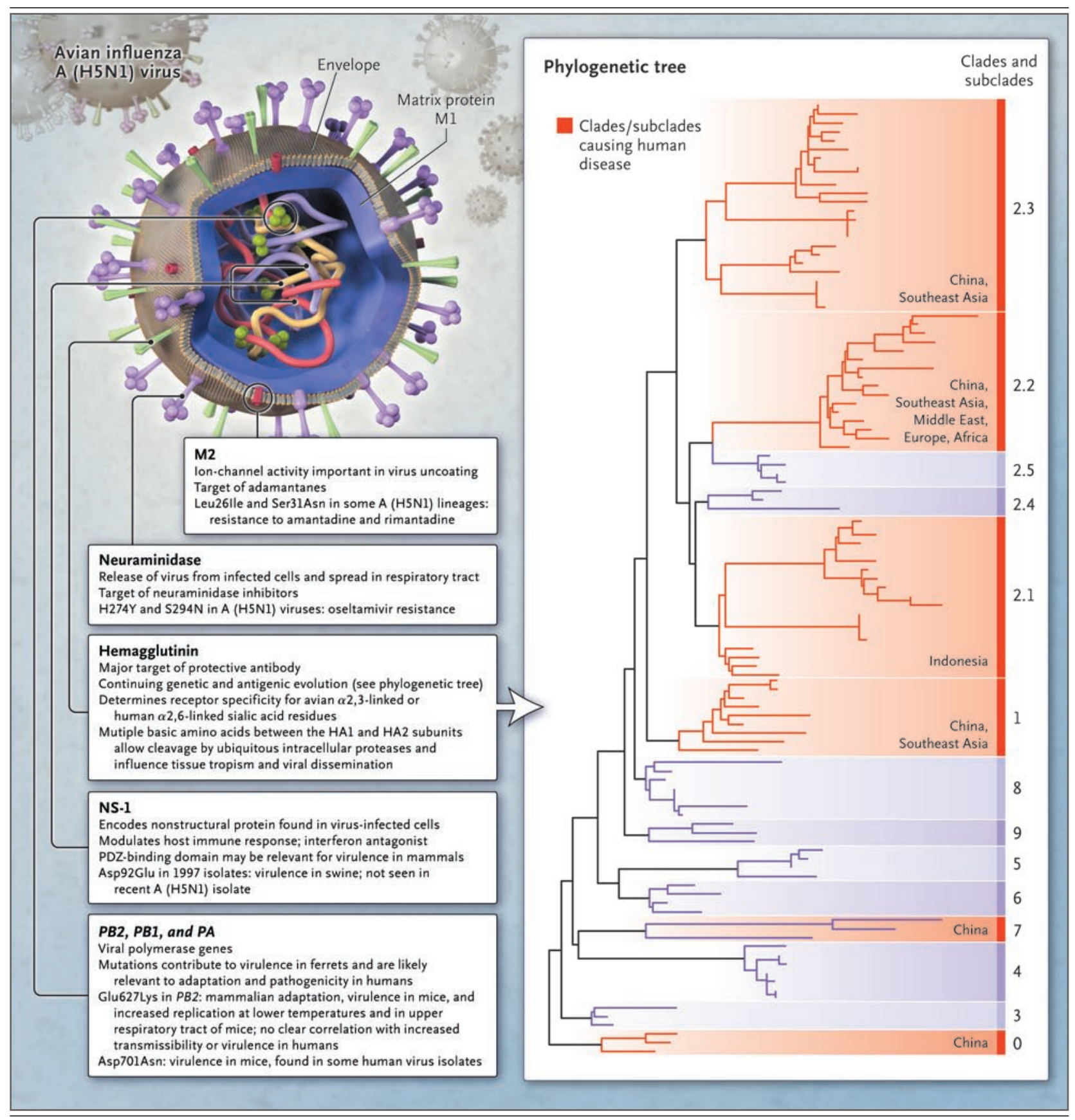

in case clusters probably acquired infection from common-source exposures to poultry, but limited, nonsustained human-to-human transmission has probably occurred during very close, unprotected contact with a severely ill patient. ${ }^{20,30,32}$ In the largest cluster, transmission probably occurred from the index case to six blood-related family members and subsequently to another family member. ${ }^{32}$ Respiratory secretions and all bodi- ly fluids, including feces, should be considered potentially infectious.

In one quarter or more of patients with influenza A (H5N1) virus infection, the source of exposure is unclear, and environment-to-human transmission remains possible. ${ }^{20,24}$ For some patients, the only identified risk factor was visiting a live-poultry market. ${ }^{34,35}$ Plausible transmission routes include contact with virus-contaminated 
fomites or with fertilizer containing poultry feces, followed by self-inoculation of the respiratory tract or inhalation of aerosolized infectious excreta. It is unknown whether influenza A (H5N1) virus infection can begin in the human gastrointestinal tract. In several patients, diarrheal disease preceded respiratory symptoms, ${ }^{36}$ and virus has been detected in feces. ${ }^{3,37}$ Acquisition of influenza A (H5N1) virus infection in the gastrointestinal tract has been implicated in other mammals. ${ }^{26}$ Drinking potable water and eating properly cooked foods are not considered to be risk factors, but ingestion of virus-contaminated products or swimming or bathing in virus-contaminated water might pose a risk.

\section{INCUBATION PERIOD}

After exposure to infected poultry, the incubation period generally appears to be 7 days or less, and in many cases this period is 2 to 5 days. In clusters in which limited, human-to-human transmission has probably occurred, the incubation period appears to be approximately 3 to 5 days, although in one cluster it was estimated to be 8 to 9 days. ${ }^{20,30}$

\section{PATHOGENESIS}

\section{VIRAL FACTORS}

The viral and host factors that determine host-restriction and disease manifestations are incompletely understood. ${ }^{38}$ Preferential binding of the influenza A (H5N1) virus to $\alpha 2,3$-linked sialic acid receptors on avian cells ${ }^{39}$ is thought to be key in preventing influenza A (H5N1) and other avian influenza viruses from readily infecting humans. Some influenza A (H5N1) viruses isolated from humans have acquired mutations that permit binding to both $\alpha 2,3$-linked sialic acid receptors and $\alpha 2,6-$ linked sialic acid receptors, ${ }^{40}$ but these mutations appear to be insufficient for efficient human-tohuman transmission. To date, influenza A (H5N1) viruses have shown no transmissibility or poor transmissibility between ferrets and between swine, and reassortment between an influenza A (H5N1) virus and an influenza A (H3N2) virus did not confer transmissibility in ferrets. ${ }^{41}$ Changes in multiple viral genes are probably required to generate a potentially pandemic influenza A (H5N1) virus.

All recent influenza A (H5N1) viruses retain a polybasic amino acid motif at the HA1-HA2 connecting peptide that is characteristic of highly pathogenic avian influenza viruses. Geographic variations in this motif have not been associated with obvious changes in the virulence of infection in humans. Amino acid substitutions in the polymerase basic protein 2 (PB2) gene are associated with mammalian adaptation, virulence in mice, and replication at temperatures present in the upper respiratory tract (Fig. 1). ${ }^{42}$ However, these mutations do not correlate with obvious differences in mortality among humans with this viral infection. , $^{3} 21$

\section{VIRAL REPLICATION}

The primary pathologic process that causes death is fulminant viral pneumonia. The target cells for replication of the influenza A (H5N1) virus include type 2 alveolar pneumocytes and macrophages. ${ }^{17,43,44}$ Bronchiolar and alveolar cells, but not epithelia from the trachea or upper respiratory tract, express detectable $\alpha 2,3$-linked sialic acid receptors. ${ }^{43-45}$ However, influenza A (H5N1) viruses replicate in ex vivo organ cultures of the upper respiratory tract, ${ }^{44}$ postmortem studies show virus in tracheal epithelia, ${ }^{17,46}$ and high titers of virus are detectable in specimens of throat and tracheal aspirates from humans infected with influenza $\mathrm{A}$ (H5N1) virus. ${ }^{3}$ These findings suggest that the initial infection may occur in either the upper or lower respiratory tract, although the latter may support more efficient replication.

Limited data show that patients with influenza A (H5N1) disease may have detectable viral RNA in the respiratory tract for up to 3 weeks, presumably because of negligible preexisting immunity and possibly viral evasion of immune responses. ${ }^{3}$ One patient with fatal infection treated with both antiviral agents and corticosteroids had viral antigen and RNA in tracheal samples on day 27 after the onset of illness. ${ }^{17}$ Viral loads in the pharynx are higher and plasma viral RNA is detected more often in patients with fatal disease than in those with nonfatal disease, indicating that levels of viral replication influence the outcome. ${ }^{3}$ The reported presence of infectious virus in the blood, cerebrospinal fluid, or viscera of several patients with fatal disease indicates that, as in birds and several mammalian species, disseminated infection occurs in some humans. $3,17,36,37,46$ A fatal influenza A (H5N1) infection in one pregnant woman who received corticosteroids for treatment of the disease was associated with virus infection of the brain, placenta, and fetus. ${ }^{17}$ Infectious virus and viral RNA have been detected 
in feces and intestines, suggesting that the virus sometimes replicates in the gastrointestinal tract. ${ }^{1,3,36,37,46}$

\section{PATHOLOGICAL FINDINGS}

The few reported autopsies of patients with influenza A (H5N1) virus infection have shown diffuse alveolar damage with hyaline membrane formation, patchy interstitial lymphoplasmacytic infiltrates, bronchiolitis with squamous metaplasia, and pulmonary congestion with varying degrees of hemorrhage. ${ }^{17,46,47}$ Acute exudative, diffuse alveolar damage with macrophages, neutrophils, and activated lymphocytes has been detected in patients who died within 2 weeks after the onset of illness. Apoptosis in alveolar cells and infiltrating leukocytes are prominent findings. ${ }^{46}$ Lymphocyte depletion occurs in the spleen, lymph nodes, and tonsils; histiocytic hyperplasia and reactive hemophagocytosis presumably result from host cytokine responses and viral infection. Edema and degeneration of myocytes in the heart and extensive acute tubular necrosis in the kidney have been observed.

\section{HOST RESPONSES}

Higher plasma levels of macrophage and neutrophil-attractant chemokines and both proinflammatory and antiinflammatory cytokines (interleukin-6, interleukin-10, and interferon- $\gamma$ ) have been observed in patients with influenza A (H5N1) virus infection - particularly in patients with fatal infection - than in patients with conventional in- fluenza. ${ }^{3}$ Plasma levels of cytokines and chemokines correlate positively with pharyngeal viral loads ${ }^{3}$ suggesting that these responses are driven by high-level viral replication. In vitro experiments involving primary human macrophages and lung pneumocytes show differential up-regulation of multiple cytokines by influenza A (H5N1) virus as compared with human influenza viruses, ${ }^{48}$ indicating that viral hyperinduction probably contributes to hypercytokinemia.

In mouse models of influenza A (H5N1) virus infection, mice with deficient induction of interleukin-6, macrophage inflammatory protein $1 \alpha$, or tumor necrosis factor $\alpha$ or its receptors ${ }^{49,50}$ and mice treated with glucocorticoids, ${ }^{50}$ had similar mortality as compared with wild-type animals; mice without interleukin-1 receptors had increased mortality. ${ }^{49}$ Tissue damage in human influenza A (H5N1) disease probably results from the combined effects of unrestrained viral infection and inflammatory responses induced by influenza A (H5N1) infection. Knowledge of the mechanisms of hypercytokinemia is insufficient to guide safe, rational immunomodulatory treatment at present.

\section{CLINICAL FEATURES}

Currently, illness due to influenza A (H5N1) viruses typically manifests as severe pneumonia that often progresses rapidly to the acute respiratory distress syndrome. The time from the onset of illness to presentation (median, 4 days) or to

\begin{tabular}{|c|c|c|c|c|c|c|}
\hline \multirow[t]{2}{*}{ Country } & \multirow[t]{2}{*}{$\begin{array}{l}\text { Predominant } \\
\text { Clade or } \\
\text { Subclade* }\end{array}$} & \multirow{2}{*}{$\begin{array}{l}\text { Case Fatality } \\
\text { Proportion } \\
\text { no. of patients/ } \\
\text { total no. (\%) }\end{array}$} & \multirow{2}{*}{\multicolumn{2}{|c|}{$\begin{array}{l}\text { Onset of Illness } \\
\text { to Hospitalization } \\
\text { no. of } \\
\text { days patients }\end{array}$}} & \multicolumn{2}{|c|}{$\begin{array}{l}\text { Onset of Illness } \\
\text { to Death }\end{array}$} \\
\hline & & & & & days & $\begin{array}{c}\text { no. of } \\
\text { patients }\end{array}$ \\
\hline Cambodia, Thailand, Vietnam $†$ & 1 & $66 / 123(54)$ & 4 & 109 & 9 & 65 \\
\hline Indonesia & 2.1 & $76 / 96(79)$ & 5 & 64 & 9 & 72 \\
\hline $\begin{array}{l}\text { Azerbaijan, Djibouti, Egypt, Iraq, } \\
\text { Nigeria, Turkey }\end{array}$ & 2.2 & $26 / 59(44)$ & 3 & 36 & 9 & 24 \\
\hline China, Laos & 2.3 & $17 / 26(65)$ & 5 & 16 & 10 & 17 \\
\hline
\end{tabular}

* The presumed clade or subclade assignment is based on the known geographic distribution of the viruses and is not verified by individual patient data. Few sequences are available for human isolates in the public database for some countries. Multiple clades and subclades have circulated in China in poultry. The numbers of patients for whom data were available are listed. The analysis was provided by Dr. Christoph Steffen and Dr. Julia Fitzner, WHO, Geneva.

$\uparrow$ Among 61 patients with documented clade 1 infection, the case fatality proportion was $75 \%$; the median time from the onset of illness to hospitalization was 5 days in 48 patients, and the median time from the onset of illness to death was 9 days in 46 patients. 
death (median, 9 to 10 days) has remained unchanged from 2003 through 2006 (Table 1). ${ }^{16} \mathrm{Ob}-$ served differences in mortality among patients with presumed clade 1 and clade 2 virus infections (Tables 1 and 2) 1,21,24,35,51 are difficult to interpret because of variations in medical practices and the time from the onset of illness to treatment among affected countries.

Febrile upper respiratory illnesses without pneumonia in children have been reported more frequently since 2005. ${ }^{20,21}$ Early consultation and antiviral therapy may have altered the clinical course of these illnesses. Less frequent gastrointestinal symptoms have been reported since 2005
(Table 2), suggesting that some manifestations of clade 1 and 2 virus infections may differ from each other. Leukopenia, lymphopenia, mild-tomoderate thrombocytopenia, and elevated levels of aminotransferases are common but not universal (Table 2). Lymphopenia and increased levels of lactate dehydrogenase at presentation have been associated with a poor prognosis. ${ }^{1,3,21,37}$ Other reported abnormalities include elevated levels of creatine phosphokinase, hypoalbuminemia, and increased D-dimer levels and changes indicative of disseminated intravascular coagulopathy. ${ }^{20,21}$

The nonspecific clinical presentation of influenza A (H5N1) disease has often resulted in mis-

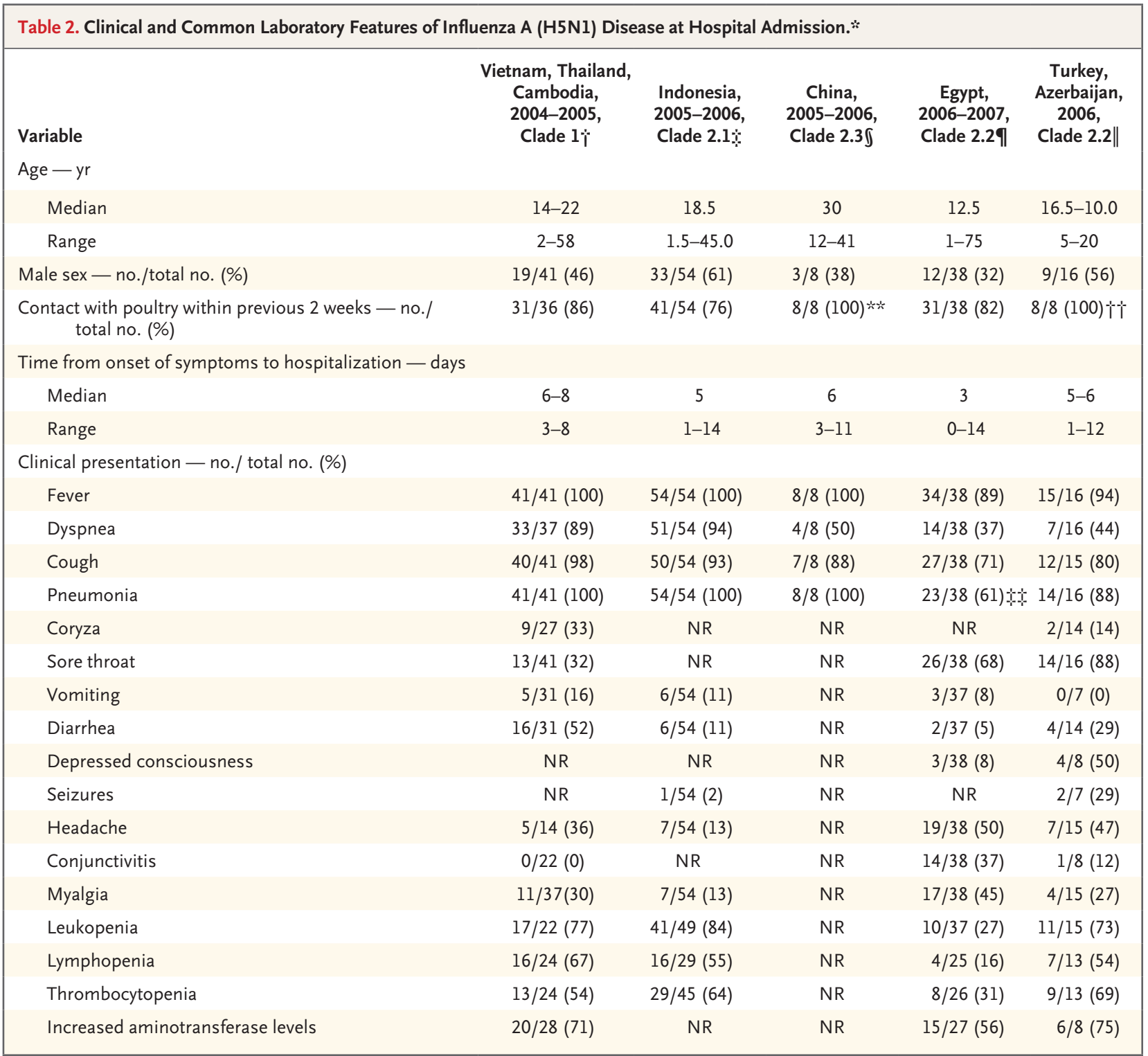




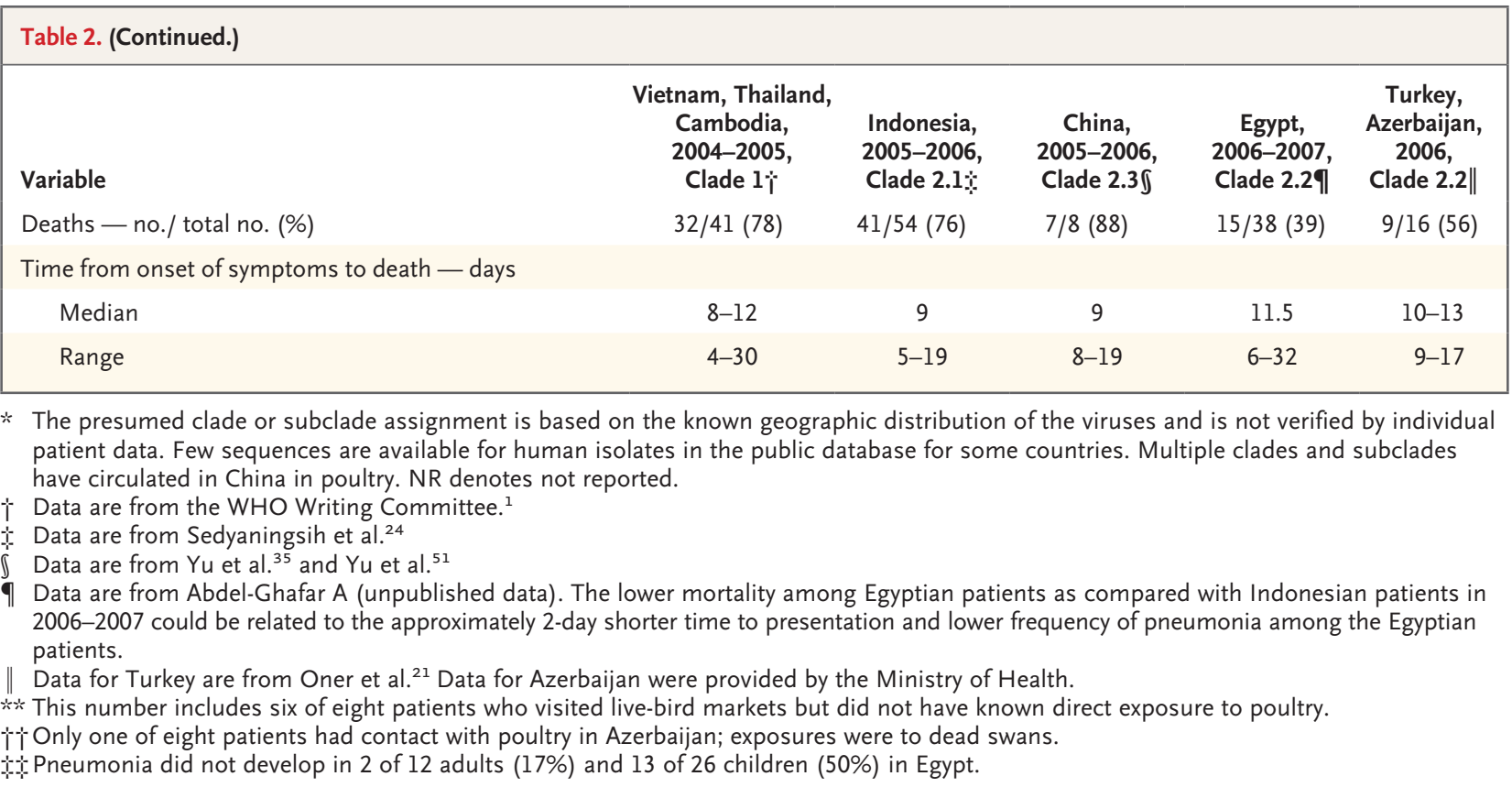

diagnosis of subsequently confirmed cases (Table 3); influenza A (H5N1) virus infection has been suspected in only a small number of patients. Health care staff should include influenza A (H5N1) virus infection in the differential diagnosis for patients who present with epidemiologic risk factors and unusual courses of illness, especially rapidly progressing pneumonia (see Fig. 2 of the Supplementary Appendix).

\section{LABORATORY DIAGNOSIS}

Detection of viral RNA by means of conventional or real-time reverse-transcriptase polymerase chain reaction remains the best method for the initial diagnosis of influenza A (H5N1). ${ }^{52}$ These assays can provide results within 4 to 6 hours and can be performed under biosafety level 2 conditions. The genetic variability of influenza A (H5N1) viruses $^{7,8}$ calls for frequent updating of primers and probes. Consequently, access to sequences from recent influenza A (H5N1) viral isolates is essential. To detect other influenza A virus infections and reduce false negative results due to mutations in the $\mathrm{H} 5$ hemagglutinin gene, a conserved influenza A gene (e.g., matrix or nucleoprotein) should also be targeted.

Diagnostic yields are higher with throat specimens than with nasal swabs because of higher viral loads of influenza A (H5N1) in the throat. ${ }^{1,3}$
However, nasal swabs are useful for detecting human influenza viruses, so collection of both specimens is recommended. If they are available, tracheal aspirates have higher viral titers and yields than specimens from the upper respiratory tract. ${ }^{3}$ Negative results in single respiratory specimens do not rule out influenza A (H5N1) virus infection, ${ }^{21}$ and repeated collection of multiple specimen types is recommended..$^{52}$ Previous antiviral treatment may reduce the diagnostic yield. Detection of influenza A (H5N1) viral RNA in feces or blood may provide prognostic information, ${ }^{3}$ but it has lower diagnostic sensitivity than influenza A (H5N1) viral RNA in respiratory specimens.

Commercially available rapid assays for influenza-antigen detection have poor clinical sensitivity for the detection of influenza A (H5N1) virus (Table 2 of the Supplementary Appendix), 1,20,21 and they do not differentiate between human and avian subtypes of influenza A viruses. Although rapid antigen tests have similar analytic sensitivity for detecting human and avian influenza $\mathrm{A}$ (H5N1) viruses, they require 1000 times higher levels of virus than viral cultures to be positive. ${ }^{53}$

The detection of anti-H5 antibodies is essential for epidemiologic investigations and may provide retrospective diagnostic confirmation in patients. Seroconversion generally occurs 2 to 3 weeks after infection. Microneutralization assays are the most reliable methods for detecting antibodies to 


\begin{tabular}{|lcc|}
\hline $\begin{array}{l}\text { Table 3. Initial Diagnosis in Patients with Confirmed Influenza A (H5N1) } \\
\text { Virus Infection.* }\end{array}$ & $\begin{array}{c}\text { Indonesia } \\
(\mathbf{N}=52)\end{array}$ & $\begin{array}{c}\text { Thailand } \\
(\mathbf{N}=\mathbf{2 5})\end{array}$ \\
\hline Diagnosis & \multicolumn{2}{|c|}{ number (percent) } \\
Pneumonia & $24(46)$ & $11(44)$ \\
Dengue virus infection & $6(12)$ & $4(16)$ \\
Typhoid fever & $2(4)$ & $0(0)$ \\
Upper respiratory illness & $14(27)$ & $4(16)$ \\
Avian influenza & $6(12)$ & $2(8)$ \\
Other & $0(0)$ & $4(16) \dagger$
\end{tabular}

* Data are from Chotpitayasunondh T and Soeroso S (unpublished data).

$\uparrow$ Tuberculosis was diagnosed in one patient, diarrhea in one patient, dizziness in one patient, and leptospirosis in one patient.
Indonesia and Turkey, ${ }^{56,57}$ although the possible clinical relevance of such differences in oseltamivir susceptibility remains to be determined. During oseltamivir therapy, the emergence of highly resistant variants with an $\mathrm{H} 274 \mathrm{Y}$ neuraminidase mutation may be associated with a fatal outcome. ${ }^{58}$ Infection by influenza A (H5N1) viruses containing an $\mathrm{N} 294 \mathrm{~S}$ mutation that causes a reduction in oseltamivir susceptibility by a factor of 12 to 15 times was reported to be present in two Egyptian patients with fatal disease before therapy, ${ }^{59}$ and avian influenza A (H5N1) viruses with reduced susceptibility to neuraminidase inhibitors are occasionally detected. ${ }^{60}$

Early treatment with oseltamivir is recommended, ${ }^{61,62}$ and data from uncontrolled clinical trials suggest that it improves survival (Table 4), although the optimal dose and duration of therapy are uncertain. Mortality remains high despite administration of oseltamivir; late initiation of therapy appears to be a major factor. Uncontrolled viral replication, as reflected in the detection of persistent pharyngeal RNA after completion of standard therapy, is associated with a poor prognosis. ${ }^{58}$ Higher levels of viral replication and slower clearance of infection probably occur in the lower respiratory tract. ${ }^{3}$ The oral bioavailability of oseltamivir in patients with severe diarrhea or gastrointestinal dysfunction related to influenza A (H5N1) virus infection or those in whom the drug has been administered extemporaneously (e.g., by means of a nasogastric tube) is uncertain.

A higher dose of oseltamivir (e.g., $150 \mathrm{mg}$ twice daily in adults) and an increased duration of therapy, for a total of 10 days, may be reasonable, given the high levels of replication of the influenza A (H5N1) virus, observations of progressive disease despite early administration of standarddose oseltamivir ( $75 \mathrm{mg}$ twice daily for 5 days in adults) within 1 to 3 days after the onset of the illness, and the proven safety of higher doses in adults with seasonal influenza, especially if there is pneumonic disease at presentation or evidence of clinical progression. ${ }^{62}$ In mouse models of amantadine-sensitive influenza A (H5N1) virus infection, as compared with monotherapy, the combination of oseltamivir and amantadine significantly increased survival rates and inhibited viral replication in the internal organs. ${ }^{64}$ No adverse pharmacologic interactions have been shown in humans. ${ }^{65}$ In areas where influenza A (H5N1) viruses are likely to be susceptible to amantadine, 


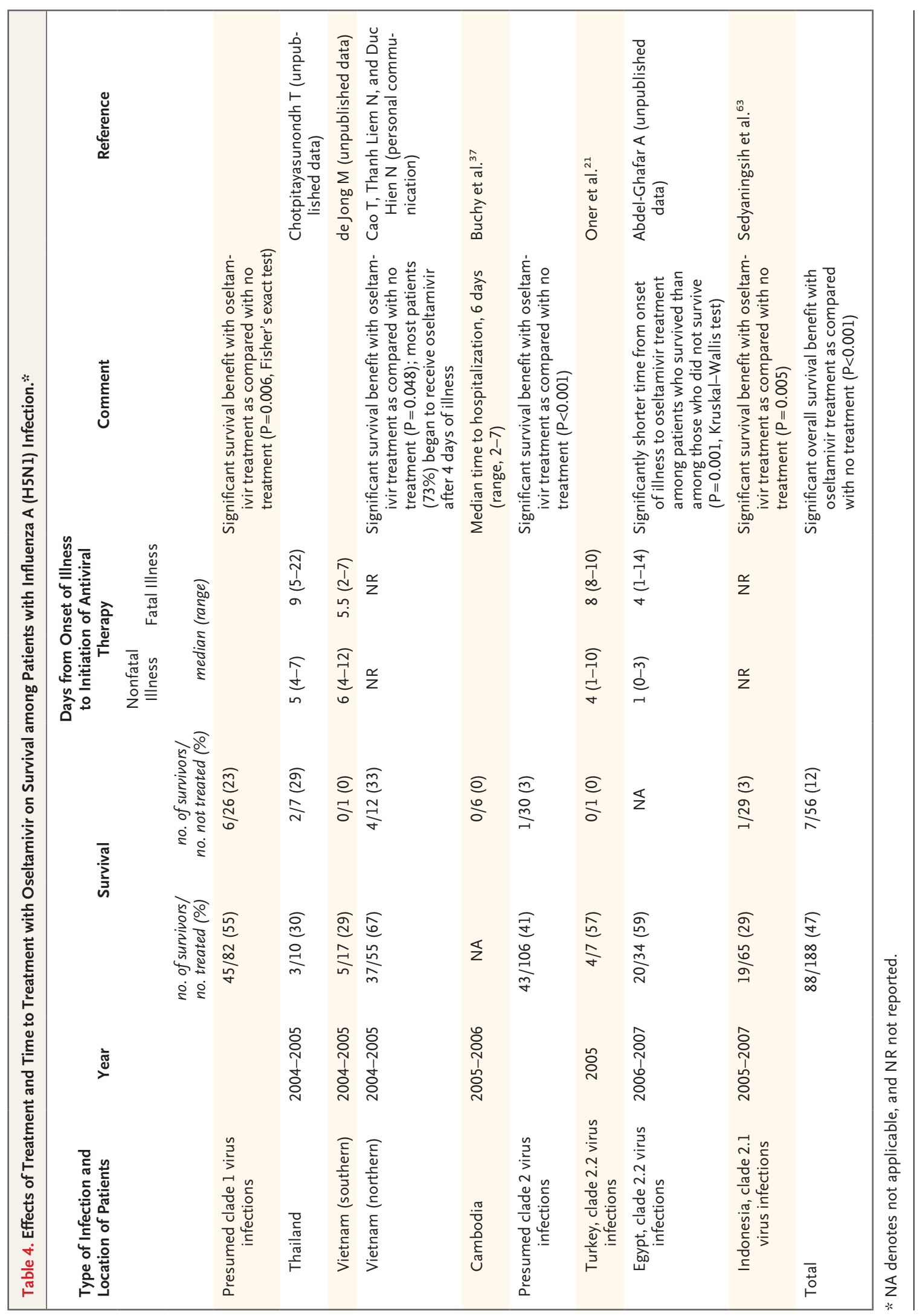


combination treatment with oseltamivir would be reasonable, especially in seriously ill patients.

Although zanamivir is active against oseltamivir-resistant variants with $\mathrm{N} 1$ neuraminidase mutations at $\mathrm{H} 274 \mathrm{Y}^{66}$ or $\mathrm{N} 294 \mathrm{~S}$, the value of inhaled zanamivir has not been studied in human influenza A (H5N1) disease. Suboptimal delivery to sites of infection in patients with pneumonic or extrapulmonary disease is a concern. Parenteral delivery of zanamivir or the neuraminidase inhibitor peramivir results in antiviral activity in animal models of influenza A (H5N1) virus infection; these agents and others are under clinical development (Table 3 of the Supplementary Appendix).

\section{OTHER TREATMENTS}

Supportive care with correction of hypoxemia and treatment of nosocomial complications remains fundamental in the management of influenza A (H5N1) disease. ${ }^{2,62}$ Corticosteroids should not be used routinely. ${ }^{62}$ Corticosteroid therapy has thus far not been shown to be effective in patients with influenza A (H5N1) virus infection, ${ }^{1}$ and prolonged or high-dose corticosteroid therapy can result in serious adverse events, including opportunistic infections such as central nervous system toxoplasmosis (Soeroso S: unpublished data). In northern Vietnam, mortality was 59\% among 29 recipients of corticosteroids, as compared with $24 \%$ among 38 persons who did not receive corticosteroids $(\mathrm{P}=0.004)$ (Cao $\mathrm{T}$, Thanh Liem $\mathrm{N}$ : personal communication). The possible value of other immunomodulators remains to be determined.

PREVENTION

Avian influenza A viruses are readily inactivated by a variety of chemical agents and physical conditions, including soaps, detergents, alcohols, and chlorination. ${ }^{67,68}$ Guidelines for the prevention of infection with influenza A (H5N1) virus in various risk groups, including poultry workers, travelers, and health care workers, are available from the U.S. Centers for Disease Control and Prevention and the WHO.

\section{ANTIVIRAL CHEMOPROPHYLAXIS}

WHO guidelines for the use of antiviral agents for prophylaxis in persons who have been exposed to influenza A (H5N1) viruses in the current pan- demic-alert period have been published. ${ }^{61}$ Mathematical models of an emerging outbreak of influenza A (H5N1) in rural Asia predict that a strategy of mass, targeted antiviral chemoprophylaxis and social-distancing measures might extinguish or delay pandemic spread of the virus. The WHO has a stockpile of oseltamivir for this purpose and is working with partners for implementation of its distribution in the event of an outbreak. 69

\section{IMMUNIZATION}

Safe and immunogenic inactivated $\mathrm{H} 5$ vaccines have been developed. ${ }^{6}$ Reverse genetics permits the rapid generation of seed viruses with attenuated virulence, but the changing antigenicity of circulating strains of influenza A (H5N1) viruses calls for new candidate vaccines from different lineages ${ }^{6}$ and the development of vaccines that elicit cross-clade immunogenicity. H5 hemagglutinin appears to be a weak human immunogen. For subvirion vaccines without adjuvants, persons who have not received a priming dose require two doses with a high hemagglutinin antigen content (Table 4 of the Supplementary Appendix). As compared with conventional subunit vaccines, certain oil-in-water adjuvant agents ${ }^{6,70,71}$ or the use of whole-virus $\mathrm{H} 5 \mathrm{~N} 1$ vaccines ${ }^{6,72,73}$ can substantially reduce the amount of vaccine antigen required to induce immune responses in persons who have not received a priming dose, and they can induce immune responses to antigenically drifted viruses. However, the specific adjuvant, formulation, dose, stability, and ratio with the antigen are important variables that require clinical testing for each candidate vaccine. Alum adjuvants have not consistently improved the responses to $\mathrm{H} 5$ vaccines, ${ }^{6,73,74}$ whereas certain proprietary adjuvants (e.g., MF59 and AS03) appear to be highly effective and allow for considerable antigensparing and cross-reactive antibody responses. . $^{6,70,71}$ These adjuvants have also been associated with increased rates of local and sometimes systemic reactogenicity.

The antibody levels required for protection against human influenza A (H5N1) illness are unclear. The durability of antibody responses is limited, but boosting with a homologous vaccine ${ }^{70}$ or virus vaccine with viral antigen from another clade $^{75}$ appears to be effective in persons who have received two priming doses. Prepriming might allow single doses of a homologous vaccine to be 
sufficient for an antigenically drifted pandemic virus. However, decisions regarding the use of vaccine before a pandemic and stockpiling require complex risk-benefit and cost-benefit analyses that include effects on the seasonal capacity of vaccine production, because the timing and cause of the next influenza pandemic are unknown, and it is unclear whether immunization of large populations could have adverse consequences.

Initial studies in children and elderly persons suggest that antibody responses to subvirion vaccines at high doses (45 or $90 \mu \mathrm{g}$ ) are similar to those in young adults. Approximately 15 to $20 \%$ of older adults have some baseline neutralizing antibodies to $\mathrm{H} 5 \mathrm{~N} 1$ virus and may have a response to a single dose. ${ }^{6}$ The mechanisms leading to these antibodies are uncertain. Other studies to date have shown that intradermal $\mathrm{H} 5$ vaccines at low doses are poorly immunogenic and may be associated with injection-site reactions. ${ }^{6}$ Intranasal live attenuated $\mathrm{H} 5$ vaccines are highly effective in animal models ${ }^{76}$ but they show a variable ability to replicate in humans and to induce immune responses. Various investigational approaches, including conserved antigen vaccines, vectored $\mathrm{H} 5$ vaccines, and other adjuvants, are being explored.

Dr. Chotpitayasunondh reports receiving grant support from Sanofi Pasteur and lecture fees from Sanofi Pasteur, GlaxoSmithKline, and Merck; and Dr. Peiris, consulting fees from GlaxoSmithKline and Novartis and travel expenses and lecture fees from Novartis, Roche, and Sanofi Pasteur. No other potential conflict of interest relevant to this article was reported.

Two authors (Drs. Hayden and Shindo) are staff members of the WHO. The authors alone are responsible for the views expressed in this article, and they do not necessarily represent the decisions or the stated policy of the WHO. The views expressed in this article do not necessarily reflect those of the other organizations whose staff participated in the WHO consultation.

We thank Drs. Christoph Steffen and Kaat Vandermaele of the WHO for their help with access to data and development of the management algorithm, Diane Ramm of the University of Virginia for her assistance in the preparation of an earlier version of the manuscript, and our colleagues in countries affected by A (H5N1) virus for their willingness to share unpublished clinical data for this article.

\section{APPENDIX}

The writing committee's affiliations are as follows: the Ministry of Health and Population, Cairo (A.-N.A.-G.); the Queen Sirikit National Institute of Child Health, Bangkok, Thailand (T.C.); the Peking University People's Hospital, Beijing (Z.G.); the Global Influenza Program, World Health Organization, Geneva (F.G.H., N.S.); the University of Virginia, Charlottesville (F.G.H.); the National Institute for Infectious and Tropical Diseases, Hanoi (N.D.H.); the Oxford University Clinical Research Unit, Hospital for Tropical Diseases, Ho Chi Minh City, Vietnam (M.D.J.); the Abulfaz Karayev Children's Hospital No. 2, Baku, Azerbaijan (A.N.); the University of Hong Kong, Hong Kong (J.S.M.P.); the National Infectious Diseases Hospital, Jakarta, Indonesia (S.S.); and the Centers for Disease Control and Prevention, Atlanta (T.M.U.).

REFERENCES

1. The Writing Committee of the World Health Organization (WHO) Consultation on Human Influenza A/H5. Avian influenza A (H5N1) infection in humans. $\mathrm{N}$ Engl J Med 2005;353:1374-85. [Erratum, N Engl J Med 2006;354:884.]

2. World Health Organization. Summary of the second WHO consultation on clinical aspects of human infection with avian influenza A (H5N1) virus. (Accessed December 20, 2007, at http://www.who.int/csr/ disease/avian_influenza/meeting19_03_ 2007/en/index.html.)

3. de Jong M, Simmons CP, Thanh TT, et al. Fatal outcome of human influenza A (H5N1) is associated with high viral load and hypercytokinemia. Nat Med 2006;12: 1203-7.

4. Chen H, Smith GJD, Li KS, et al. Establishment of multiple sublineages of H5N1 influenza virus in Asia: implications for pandemic control. Proc Natl Acad Sci U S A 2006;103:2845-50.

5. Webster RG, Govorkova EA. H5N1 Influenza - continuing evolution and spread. N Engl J Med 2006;355:2174-7.

6. World Health Organization. Third WHO meeting on evaluation of pandemic influenza prototype vaccines in clinical trials, Geneva, 15-16 February 2007. (Accessed December 20, 2007, at http://www.who. int/vaccine_research/diseases/influenza/ meeting_150207/en/.)

7. Idem. Antigenic and genetic characteristics of $\mathrm{H} 5 \mathrm{~N} 1$ viruses and candidate $\mathrm{H} 5 \mathrm{~N} 1$ vaccine viruses developed for potential use as pre-pandemic vaccines. March 2007. (Accessed December 20, 2007, at http:// www.who.int/csr/disease/avian_influenza/ guidelines/h5n1virus/en/index.html.)

8. Smith GJD, Fan XH, Wang J, et al. Emergence and predominance of an H5N1 influenza variant in China. Proc Natl Acad Sci U S A 2006;103:16936-41.

9. Gauthier-Clerc $M$, Lebarbenchon $C$, Thomas F. Recent expansion of highly pathogenic avian influenza H5N1: a critical review. Ibis 2007;149:202-14.

10. Kilpatrick AM, Chmura AA, Gibbons DW, Fleischer RC, Marra PP, Daszak P. Predicting the global spread of H5N1 avian influenza. Proc Natl Acad Sci U S A 2006; 103:19368-73.

11. Ducatez MF, Olinger CM, Owoade AA, et al. Avian flu: multiple introductions of H5N1 in Nigeria. Nature 2006;442:37.
12. Winker K, McCracken KG, Gibson D, et al. Movements of birds and avian influenza from Asia into Alaska. Emerg Infect Dis 2007;13:547-52.

13. Fielding R, Bich TH, Quang LN, et al. Live poultry exposures, Hong Kong and Hanoi, 2006. Emerg Infect Dis 2007;13: 1065-7.

14. Vong S, Coghlan B, Mardy S, et al. Low frequency of poultry-to-human H5N1 virus transmission, Southern Cambodia, 2005. Emerg Infect Dis 2006;12:15427.

15. World Health Organization. Cumulative number of confirmed human cases of avian influenza $\mathrm{A} /(\mathrm{H} 5 \mathrm{~N} 1)$ reported to WHO. (Accessed December 20, 2007, at http:/l www.who.int/csr/disease/avian_influenza/ country/cases_table_2007_12_14/en/index. html.)

16. Idem. Update: WHO-confirmed human cases of avian influenza A(H5N1) infection, 25 November 2003-24 November 2006. Wkly Epidemiol Rec 2007;82:41-8. (Accessed December 20, 2007, at http:// www.who.int/wer/2007/wer8206.pdf.)

17. Gu J, Xie Z, Gao Z, et al. H5N1 infection of the respiratory tract and beyond: 
a molecular pathology study. Lancet 2007; 370:1137-45.

18. Park AW, Glass K. Dynamic patterns of avian and human influenza in east and southeast Asia. Lancet Infect Dis 2007; 7:543-8.

19. Ortiz JR, Wallis TR, Katz MA, et al. No evidence of avian influenza A (H5N1) among returning US travelers. Emerg Infect Dis 2007;13:294-7.

20. Kandun IN, Wibisono H, Sedyaningsih ER, et al. Three Indonesian clusters of H5N1 virus infection in 2005. N Engl J Med 2006;355:2186-94.

21. Oner AF, Bay A, Arslan S, et al. Avian influenza A (H5N1) infection in eastern Turkey in 2006. N Engl J Med 2006;355: 2179-85.

22. Dinh PN, Long HT, Tien NTK, et al. Risk factors for human infection with avian influenza A H5N1, Vietnam, 2004. Emerg Infect Dis 2006;12:1841-7.

23. Areechokchai D, Jiraphongsa C, Laosiritaworn Y, Hanshaoworakul W, O'Reilly $\mathrm{M}$. Investigation of avian influenza (H5N1) outbreak in humans - Thailand, 2004. MMWR Morb Mortal Wkly Rep 2006;55: Suppl 1:3-6.

24. Sedyaningsih ER, Isfandari $\mathrm{S}$, Setiawaty V, et al. Epidemiology of cases of H5N1 virus infection in Indonesia, July 2005-June 2006. J Infect Dis 2007;196: 522-7.

25. Human avian influenza in Azerbaijan, February-March 2006. Wkly Epidemiol Rec 2007;81:183-188. (Accessed December 20, 2007, at http://www.who.int/ wer/2006/wer8118.pdf.)

26. Thiry E, Zicola A, Addie D, et al. Highly pathogenic avian influenza H5N1 virus in cats and other carnivores. Vet Microbiol 2007;122:25-31.

27. Mumford E, Bishop J, Hendrickx S, Embarek PB, Perdue M. Avian influenza H5N1: Risks at the human-animal interface. Food Nutr Bull 2007;28:Suppl:S357S363.

28. Leschnik M, Weikel J, Möstl K, et al. Subclinical infection with avian influenza A (H5N1) virus in cats. Emerg Infect Dis 2007;13:243-7.

29. Songserm T, Amonsin A, Jam-on R, et al. Fatal avian influenza A H5N1 in a dog. Emerg Infect Dis 2006;12:1744-7.

30. Ungchusak K, Auewarakul P, Dowell $\mathrm{SF}$, et al. Probable person-to-person transmission of avian influenza A (H5N1). N Engl J Med 2005;352:333-40.

31. Olsen SJ, Ungchusak K, Sovann L, et al. Family clustering of avian influenza A (H5N1). Emerg Infect Dis 2005;11:1799801.

32. World Health Organization. Avian influenza - situation in Indonesia - update 16. 2006. (Accessed December 20, 2007, at http://www.who.int/csr/don/2006_05_ 31/en/print.html.)
33. Pitzer VE, Olsen SJ, Bergstrom CT, Dowell SF, Lipsitch M. Little evidence for genetic susceptibility to influenza A (H5N1) from family clustering data. Emerg Infect Dis 2007;13:1074-6.

34. Wang M, Di B, Zhou D-H, et al. Food markets with live birds as source of avian influenza. Emerg Infect Dis 2006;12: 1773-5.

35. Yu H, Feng Z, Zhang X, et al. Human influenza A (H5N1) cases, urban areas of People's Republic of China, 2005-2006. Emerg Infect Dis 2007;13:1061.

36. de Jong MD, Cam BV, Qui PT, et al Fatal avian influenza A (H5N1) in a child presenting with diarrhea followed by coma. N Engl J Med 2005;352:686-91.

37. Buchy P, Mardy S, Vong S, et al. Influenza $\mathrm{A} / \mathrm{H} 5 \mathrm{~N} 1$ virus infection in humans in Cambodia. J Clin Virol 2007;39:164-8. 38. Peiris JSM, de Jong MD, Guan Y. Avian influenza virus (H5N1): a threat to human health. Clin Microbiol Rev 2007;20:243-67. 39. Stevens J, Blixt O, Tumpey TM Taubenberger JK, Paulson JC, Wilson IA Structure and receptor specificity of the hemagglutinin from an $\mathrm{H} 5 \mathrm{~N} 1$ influenza virus. Science 2006;312:404-10.

40. Yamada S, Suzuki Y, Suzuki T, et al. Haemagglutinin mutations responsible for the binding of $\mathrm{H} 5 \mathrm{~N} 1$ influenza A viruses to human-type receptors. Nature 2006 444:378-82.

41. Maines TR, Chen LM, Matsuoka Y, et al. Lack of transmission of H5N1 avianhuman reassortant influenza viruses in a ferret model. Proc Natl Acad Sci U S A 2006;103:12121-6.

42. Hatta $M$, Hatta $Y$, Kim JH, et al Growth of H5N1 influenza A viruses in the upper respiratory tracts of mice. PloS Pathog 2007;3:1374-9.

43. van Riel D, Munster VJ, de Wit E, et al H5N1 virus attachment to lower respiratory tract. Science 2006;312:399.

44. Nicholls JM, Chan MCW, Chan WY, et al. Tropism of avian influenza A (H5N1) in the upper and lower respiratory tract. Nat Med 2007;13:147-9.

45. Shinya K, Ebina M, Yamada S, Ono M, Kasai N, Kawaoka Y. Avian flu: influenza virus receptors in the human airway. $\mathrm{Na}-$ ture 2006;440:435-6.

46. Uiprasertkul M, Kitphati TC, Pathavathana $\mathrm{P}$, et al. Apoptosis and pathogenesis of avian influenza A (H5N1) virus in humans. Emerg Infect Dis 2007;13:708-12. 47. Ng WF, To KF, Lam WWL, Ng TK, Lee KC. The comparative pathology of severe acute respiratory syndrome and avian influenza A subtype H5N1 - a review. Hum Pathol 2006;37:381-90.

48. Chan MC, Cheung CY, Chui WH, et al. Proinflammatory cytokine responses induced by influenza A (H5N1) viruses in primary human alveolar and bronchia epithelial cells. Respir Res 2005;6:135.
49. Szretter KJ, Gangappa S, Lu X, et al. Role of host cytokine responses in the pathogenesis of avian H5N1 influenza viruses in mice. J Virol 2007;81:273644.

50. Salomon R, Hoffmann E, Webster RG. Inhibition of the cytokine response does not protect against lethal H5N1 influenza infection. Proc Natl Acad Sci U S A 2007;104:12479-81.

51. Yu H, Shu Y, Hu S, et al. The first confirmed human case of avian influenza A (H5N1) in Mainland China. Lancet 2006; 367:84.

52. World Health Organization. Collecting, preserving and shipping specimens for the diagnosis of avian influenza A (H5N1) virus infection: guide for field operations. (Accessed December 20, 2007, at http:// www.who.int/csr/resources/publications/ surveillance/whocdscsredc2004.pdf.)

53. Chan KH, Lam SY, Puthavathana P, et al. Comparative analytical sensitivities of six rapid influenza A antigen detection test kits for detection of influenza A subtypes H1N1, H3N2 and H5N1. J Clin Virol 2007;38:169-71.

54. Nefkens I, Garcia JM, Ling CS, et al. Hemagglutinin pseudotyped lentiviral particles: characterization of a new method for avian H5N1 influenza sero-diagnosis. J Clin Virol 2007;39:27-33.

55. Yen HL, Monto AS, Webster RG, Govorkova EA. Virulence may determine the necessary duration and dosage of oseltamivir treatment for highly pathogenic A/ Vietnam/1203/04 (H5N1) influenza virus in mice. J Infect Dis 2005;192:665-72.

56. Govorkova EA, Ilyushina NA, Boltz DA, Douglas A, Yilmaz N, Webster RG. Efficacy of oseltamivir therapy in ferrets inoculated with different clades of H5N1 influenza virus. Antimicrob Agents Chemother 2007;51:1414-24.

57. McKimm-Breschkin J, Selleck P, Usman TB, Johnson M. Reduced sensitivity of influenza A (H5N1) to oseltamivir. Emerg Infect Dis 2007;13:1354-7.

58. de Jong MD, Thanh TT, Khanh TH, et al. Oseltamivir resistance during treatment of influenza A (H5N1) infection. N Engl J Med 2005;353:2667-72.

59. Saad MD, Boynton BR, Earhart KC, et al. Detection of oseltamivir resistance mutation N294S in humans with influenza A H5N1. In: Program and abstracts of the Options for the Control of Influenza Conference, Toronto, June 17-23, 2007:228. abstract.

60. Hurt AC, Selleck P, Komadina N, Shaw R, Brown L, Barr IG. Susceptibility of highly pathogenic $\mathrm{A}(\mathrm{H} 5 \mathrm{~N} 1)$ avian influenza viruses to the neuraminidase inhibitors and adamantanes. Antiviral Res 2007;73:228-31.

61. World Health Organization. WHO rapid advice guidelines on pharmacologi- 
cal management of humans infected with avian influenza A (H5N1) virus. 2006. (Accessed December 20, 2007, at http:// www.who.int/medicines/publications/ WHO_PSM_PAR_2006.6.pdf.) 62. Idem. Clinical management of human infection with avian influenza A (H5N1) virus. 2007. (Accessed December 20 2007, at http://www.who.int/csr/disease/ avian_influenza/guidelines / clinicalmanagement07/pdf.)

63. Sedyaningsih ER, Isfandari S, Setyaway $\mathrm{V}$, et al. Clinical features of avian influenza A (H5N1) infection in Indonesia, July 2005-April 2007. In: Abstract book for the Options for the Control of Influenza VI Conference, Toronto, June 17-23, 2007:329. abstract.

64. Ilyushina NA, Hoffmann E, Solomon R, Webster RG, Govorkova EA. Amantadine-oseltamivir combination therapy for $\mathrm{H} 5 \mathrm{~N} 1$ influenza virus infection in mice. Antivir Ther 2007;12:363-70.

65. Morrison D, Roy S, Rayner C, et al. A randomized, crossover study to evaluate the pharmacokinetics of amantadine and oseltamivir administered alone and in combination. PLoS Clin Trials (in press)

66. Le QM, Kiso M, Someya K, et al. Avian flu: isolation of drug-resistant $\mathrm{H} 5 \mathrm{N1}$ virus. Nature 2005;437:1108. [Erratum, Nature 2005;438:754.]
67. De Benedictis P, Beato MS, Capua I. Inactivation of avian influenza viruses by chemical agents and physical conditions: a review. Zoonoses Public Health 2007;54: 51-68.

68. Rice EW, Adcock NJ, Sivaganesan M, Brown JD, Stallknecht DE, Swayne D. Chlorine inactivation of highly pathogenic avian influenza virus (H5N1). Emerg Infect Dis 2007;13:1568-70.

69. World Health Organization. WHO interim protocol: rapid operations to contain the initial emergence of pandemic influenza. Updated October 2007. (Accessed December 20, 2007, at http://www.who. int/csr/disease/avian_influenza/guidelines/ draftprotocol/en/index.html.)

70. Stephenson I, Bugarini R, Nicholson $\mathrm{KG}$, et al. Cross-reactivity to highly pathogenic avian influenza H5N1 viruses after vaccination with nonadjuvanted and MF59adjuvanted influenza A/Duck/Singapore/97 (H5N3) vaccine: a potential priming strategy. J Infect Dis 2005;191:1210-5.

71. Leroux-Roels I, Borkowski A, Vanwolleghem $\mathrm{T}$, et al. Antigen sparing and cross-reactive immunity with an adjuvanted $\mathrm{rH} 5 \mathrm{~N} 1$ prototype pandemic influenza vaccine: a randomised controlled trial. Lancet 2007;370:580-9.

72. Lin J, Zhang J, Dong X, et al. Safety and immunogenicity of an inactivated ad- juvanted whole-virion influenza A (H5N1) vaccine: a phase I randomised controlled trial. Lancet 2006;368:991-7.

73. Barrett N. Safety and immunogenicity of a cell culture (vero) derived whole virus H5N1 vaccine: a Phase I/II dose escalation study. In: Program of the IX International Symposium on Respiratory Viral Infections, Hong Kong, March 3-6, 2007. abstract.

74. Bresson JL, Perronne C, Launay O, et al. Safety and immunogenicity of an inactivated split-virion influenza A/Vietnam/ 1194/2004 (H5N1) vaccine: phase I randomised trial. Lancet 2006;367:1657-64. 75. Goji N, Nolan C, Hill H, Wolff M, Rowe T, Treanor J. Immune responses of healthy subjects to a single dose of intramuscular inactivated influenza A/Vietnam/ 1203/2004 (H5N1) vaccine after priming with an antigenic variant. In: Final program and abstracts of the 44th Annual Meeting of IDSA, Toronto, October 12-15, 2006:64. abstract.

76. Lu X, Edwards LE, Desheva JA, et al. Cross-protective immunity in mice induced by live-attenuated or inactivated vaccines against highly pathogenic influenza A (H5N1) viruses. Vaccine 2006;24:658893.

(C) World Health Organization 2008

All rights reserved. Published with permission from the World Health Organization. to the Journal's home page (www.nejm.org) and register by entering their names and subscriber numbers as they appear on their mailing labels. After this one-time registration, subscribers can use their passwords to log on for electronic access to the entire Journal from any computer that is connected to the Internet. Features include a library of all issues since January 1993 and abstracts since January 1975, a full-text search capacity, and a personal archive for saving articles and search results of interest. All articles can be printed in a format that is virtually identical to that of the typeset pages. Beginning 6 months after publication, the full text of all Original Articles and Special Articles is available free to nonsubscribers who have completed a brief registration. 